\title{
Attitudinal barriers from the perspective of people with physical disabilities
}

\section{Avaliação das atitudes frente a incapacidades na perspectiva de pessoas com deficiências físicas}

Flávia Canale Cabral ${ }^{1}$, (D) André Tadeu Sugawara ${ }^{1}$, Marta Imamura², (D Linamara Rizzo Battistella ${ }^{2}$

${ }^{1}$ Instituto de Medicina Física e Reabilitação do Hospital das Clínicas, Universidade de São Paulo ${ }^{2}$ Departamento de Medicina Legal, Ética Médica e Medicina Social e do Trabalho, Faculdade de Medicina, Universidade de São Paulo

\section{Corresponding}

André Tadeu Sugawara

E-mail: andre.sugawara@hc.fm.usp.br

Submitted: November 27, 2020 Accepted: February 26, 2021

\section{How to cite}

Cabral FC, Sugawara AT, Imamura M, Battistella LR. Attitudinal barriers from the perspective of people with physical disabilities. Acta Fisiatr. $2021 ; 28(1): 1-6$

\subsection{6/issn.2317-0190.v28i1a184308}

\section{BY NC SA}

This work is licensed under a Creative Commons Attribution 4.0 International

\begin{abstract}
Objective:To quantify attitudes toward disabilities, perceived by persons with disabilities (PWDs) treated at a university hospital in Brazil, as well as to determine whether PWDperceived attitudinal barriers correlate with various factors. Methods: This was a crosssectional, observational study of PWDs who completed the Attitudes to Disability Scale for persons with physical disabilities (ADS-D), which quantifies the perceived attitudinal barrier, the Hospital Anxiety and Depression Scale and the Functional Independence Measure (FIM). The data were correlated with sex, income, depression, FIM score, type of disability and time since the onset of disability. Results: We evaluated 68 patients $50.0 \%$ with a spinal cord injury, $38.2 \%$ with one or more amputated limbs and $11.8 \%$ with hemiplegia - of whom $66.2 \%$ were male, with a mean age of $39.33 \pm 12.89$ years, a mean of $10.95 \pm 4.25$ years of schooling, a median time since the onset of disability of 20.5 months (range, 10.5-33.5 months) and a median FIM score of 110.5 (range, 94-116.5). Of the 68 patients, $55.9 \%$ perceived their income to be below the national average, and depression was observed in $11.76 \%$. The mean ADS-D total score $(61.29 \pm 8.75)$ did not correlate with sex, functionality, type of disability or time since the onset of disability. The perceived magnitude of the attitudinal barrier correlated with income ( $\beta$-coefficient: -3.91; $p=0.001$ ) and depression $(\beta=-1.74 ; p<0.0001)$. Conclusion: Attitudinal barriers are influenced by income as a facilitator of inclusion and by depression as a barrier to inclusion.
\end{abstract}

Keywords: Disabled Persons, Attitude, Barriers to Access of Health Services, Surveys and Questionnaires

\section{RESUMO}

Objetivo: Quantificar as atitudes frente a incapacidades, percebidas pelas pessoas com deficiências (PCDs) atendidas em hospital universitário no Brasil, assim como determinar se as barreiras atitudinais percebidas se correlacionam com outros fatores. Métodos: Este é um estudo observacional transversal, onde a amostra de PCDs completou a Escala de Atitudes Frente a Incapacidades para Pessoas com Incapacidades Físicas (ADS-D), que quantifica a barreira atitudinal percebida, a Escala Hospitalar de Ansiedade e Depressão e a Medida de Independência Funcional (MIF). Os dados foram correlacionados com sexo, renda, depressão, valor da MIF, tipo de deficiência e tempo de deficiência. Resultados: Foram avaliados 68 pacientes - 50,0\% com lesão medular, 38,2\% com amputações e $11,8 \%$ com hemiplegia - dos quais $66,2 \%$ eram do sexo masculino, com média de idade de $39,33( \pm 12,89)$ anos, média de $10,95( \pm 4,25)$ anos de estudo, mediana de 20,5 meses (intervalo de 10,5-33,5 meses) de tempo de deficiência, mediana de valor da MIF de 110,5 (intervalo de 94-116,5). Dos 68 pacientes, 55,9\% declararam renda abaixo da média nacional e depressão foi observada em $11,76 \%$. A média da ADS-D total $(61,29 \pm 8,75)$ não foi associada ao sexo, nível funcional, tipo ou tempo de deficiência. Renda ( $\beta$-coefficient: $-3,91 ; p$ : 0,001$)$ e sintomas depressivos $(\beta=-$ $1,74 ; p<0,0001)$ se correlacionaram com a magnitude da barreira atitudinal percebida. Conclusão: As barreiras atitudinais são influenciadas pela renda, como facilitador de inclusão, e pela depressão, como entrave à inclusão.

Palavras-chaves: Pessoas com Deficiência, Atitude, Barreiras ao Acesso aos Cuidados de Saúde, Inquéritos e Questionários 


\section{INTRODUCTION}

The World Health Organization (WHO) defines disability, via the International Classification of Functioning, Disability and Health (ICF), as an alteration in the structure or function of an organ or system. ${ }^{1}$ Disability alters functionality, which can be qualified in terms of capacity and performance. Capacity is defined as the maximum functionality that a person can achieve, in a standard (ideal), uniform environment, whereas performance is defined as the functioning of a person in real life, where environmental factors act as barriers or facilitators. ${ }^{1}$

The dissociation between the functional potential (capacity) of a person in an ideal world and the actual functioning (performance) of that person in a reality full of barriers (obstacles and difficulties of any physical, organisational, political or attitudinal nature) and facilitators (factors of any nature that increase functionality) represents an opportunity to minimise disability and promote functionality through expertise in the field of physical and rehabilitation medicine. ${ }^{1}$

Persons with disabilities (PWDs), the largest recognised minority worldwide, ${ }^{2}$ routinely face an enormous number of barriers that limit their functionality. Unlike physical barriers, which are visible and certainly represent a problem to be solved, attitudinal barriers are invisible. ${ }^{3}$ The latter are often underestimated because there is limited awareness of their existence on the part of the general population. Although the term "attitude" has historically been defined in various manners, there is a consensus that attitude is an assessment of persons, groups, objects, ideas or situations, and that it can be positive (affinity) or negative (aversion). ${ }^{4}$ Attitude is influenced by personal and socio-cultural factors, and it can change over time. 3 Population-based surveys have shown that the attitude of people in general toward PWDs can be discriminatory and prejudiced, causing segregation, paternalism, infantilisation or indifference, all of which affect the self-image, identity, functionality and social participation of PWDs. ${ }^{3,5-7}$

According to the 2011 WHO World Report on Disability, ${ }^{2}$ negative attitudes explain, in part, differences between the experiences of PWDs and those of the general population. For example, PWDs have less access to education, lower employability rates and higher poverty rates. ${ }^{2}$ It is thought that attitudinal barriers can be removed by increasing public awareness and understanding of disabilities, items that are part of the current WHO recommendations on disabilities. ${ }^{2}$

Identifying the factors that limit inclusion and measuring those factors constitute the first step in developing strategies on how to expand it. $^{8}$ Rehabilitation of a PWD includes planning and implementing strategies aimed at minimising the dissociation between capacity and performance. According to the ICF, ${ }^{2}$ assessing the relationship between the person and the environment, in order to quantify the factors that limit functionality, is important for achieving rehabilitation goals. Although there have been many qualitative studies in this area, ${ }^{3,6,7}$ there is a paucity of quantitative studies. Through a multicentre study conducted in 16 countries, the WHO developed the Attitudes to Disability Scale (ADS), with the objective of evaluating and measuring the attitudinal barriers faced by PWDs. ${ }^{8}$ There are versions of the ADS for persons with physical disabilities, designated the ADS-D, and for persons with intellectual disabilities. ${ }^{8-13}$ The ADS was translated to
Portuguese and has been validated for use in Brazil since 2015. ${ }^{11,13}$

\section{OBJECTIVE}

The primary objective of this study was to quantify, through the use of the ADS-D, the attitudinal barriers perceived by PWDs. A secondary objective was to determine whether attitudinal factors correlate with sex, income, depression, functional level, the type of disability and the time since the onset of disability.

\section{METHODS}

This was a cross-sectional study involving PWDs treated at the Institute of Physical and Rehabilitation Medicine of the Hospital das Clínicas, operated by the University of São Paulo School of Medicine, in the city of São Paulo, Brazil. The sample size calculation was based on the study conducted in China by Zheng et al. ${ }^{10}$ and on the study in which the ADS was validated for use in Brazil. ${ }^{11}$ In those two studies, the mean ADS total score was 50.1 and 58.3, respectively, both with standard deviations close to 7. Considering the average of the mean ADS total scores found in those two studies (54.24) as the expected value, we found that the minimum sample size required to achieve a power $(\beta)$ of $80 \%$ at a significance level $(\alpha)$ of $5 \%$ was 27 patients. Given the secondary objective of looking for correlations with the variables sex, income, depression, the type of disability and the time since the onset of disability, we determined that an additional 40 patients would be required. Therefore, the optimal sample size was calculated to be 67 patients.

We included patients with motor disabilities who were between 18 and 65 years of age. Patients with hearing, visual or intellectual disabilities were excluded, as were those with cognitive impairment and those who were illiterate. We also excluded data for patients who dropped out of the study (for any reason) and for those who did not answer at least $75 \%$ of the questions posed.

The study was approved by the Hospital das Clínicas Committee for the Analysis of Research Projects (CAAE. 72071317.6.0000.0068). All participating patients gave written informed consent.

The patients were evaluated with a variety of instruments. We applied the following instruments: a sociodemographic questionnaire; the ADS-D; the Hospital Anxiety and Depression Scale (HADS); and the Functional Independence Measure (FIM).

The sociodemographic questionnaire was devised by Bredemeier. ${ }^{13}$ It was applied in order to collect data on age, sex, marital status, housing conditions, level of education, occupation, income, the time since the onset of disability, the subjective degree of visibility of the disability and the subjective effect that the disability has on the personal life of the individual.

The ADS-D is a cross-cultural instrument that was developed by the WHO Quality of Life Group and has been validated for use in Brazil. ${ }^{8}$ The ADS-D assesses attitudes toward disabilities from the perspective of the PWDs. ${ }^{11,13}$ It is a self-report questionnaire comprising 16 items, each scored from 1 to 5, higher scores indicating attitudes toward disability 
that are more positive; that is, higher scores translate to lower attitudinal barriers. The 16 ADS-D items are grouped into four sub-scales of four items each: Inclusion-comprising the items relationships, inclusion, burden [on] society and burden [on the] family; Discrimination-comprising the items ridicule, exploitation, irritation and ignorance; Gains-comprising the items emotional strength, maturity, achievement and determination; and Prospects - comprising the items sexuality, underestimation, optimism and future prospects. The evaluators, in a standardised way, provide subjects with guidance on how to mark the scale based on the experiences the latter have had in their real everyday environment.

The HADS, which is an internationally accepted instrument, ${ }^{14-16}$ has also been validated for use in Brazil. ${ }^{16}$ The HADS comprises 14 items, each scored on a four-point scale: seven of the items are related to anxiety; and seven are related to depression (HADS-D sub-scale). In the present study, the HADS was applied for screening, patients with an HADS-D score $\geq 9$ being considered positive for signs of depression.

The FIM, which quantifies the degree of assistance needed in order to perform activities of daily living, is widely used by rehabilitation services. ${ }^{17,18}$ In the present study, the FIM was used in order to evaluate functionality data collected from medical records.

All statistical calculations were performed in Stata software, version 15.0 for Windows (Stata Corp., College Station, TX, USA). Categorical variables are presented as absolute and relative frequencies. Numerical variables are presented as median (interquartile range) or as mean \pm standard deviation, depending on their distribution (as determined with the Shapiro-Wilk test). To compare the mean ADS-D results (total score and sub-scale scores) with the dichotomous variables sex (male or female) and HADS-D score $(\geq 9$ or $<9$ ), we used Student's t-tests. All tests were two-tailed, with Bonferroni correction, and values of $p<0.05$ were considered statistically significant.

To compare the mean ADS-D results (total score and subscale scores) with the types of disabilities, we performed analysis of variance. The potential predictors of attitudinal barriers measured by the ADS-D (age, sex, income, FIM score, HADS-D score and time since the onset of disability) were investigated by stepwise multiple linear regression, followed by linear regression for the variables showing the highest chance of being predictors of such barriers.

\section{RESULTS}

Between August 2017 and January 2018, a total of 68 individuals under treatment at the Institute of Physical and Rehabilitation Medicine of the Hospital das Clínicas were included in the study (Table 1 ). The mean age was $39.33 \pm$ 12.89 years. Of the 68 patients in the sample, $45(66.2 \%)$ were male and $23(33.8 \%)$ were female. The majority $(52.9 \%)$ of the patients were living with a steady partner (married or cohabiting). Although the majority (63.3\%) of the patients in our sample required a caregiver, only $1.5 \%$ were institutionalised. Of the 68 patients, 39 (57.4\%) had unpaid caregivers (family members). As can be seen in Table 2, there was a mean of $10.95 \pm 4.25$ years of schooling in the sample and $64.7 \%$ of the atients had a high school or college degree.
Table 1. Sociodemographic characteristics of the sample

\begin{tabular}{lc}
\hline \multicolumn{1}{c}{ Characteristic } & $(\boldsymbol{n}=68)$ \\
\hline Age (years), mean \pm SD & $39.33 \pm 12.89$ \\
Female, $\mathbf{n}$ (\%) & $23(33.8)$ \\
Male, $\mathbf{n}$ (\%) & $45(66.2)$ \\
Marital status, $\mathbf{n}$ (\%) & \\
Single & $25(36.8)$ \\
Separated & $1(1.5)$ \\
Divorced & $4(5.9)$ \\
Widowed & $2(2.9)$ \\
Married & $25(36.8)$ \\
Steady partner & $11(16.2)$ \\
Living conditions, $\mathbf{n}$ (\%) & \\
Living at home, without a caregiver & $24(35.3)$ \\
Living at home, with support from unpaid caregivers & $39(57.4)$ \\
Living at home, with support from paid caregivers & $3(4.4)$ \\
Institutionalized, with support from paid & $1(1.5)$ \\
No data & $1(1.5)$ \\
\hline
\end{tabular}

SD: standard deviation

Table 2. Academic and occupational characteristics of the sample

\begin{tabular}{|c|c|}
\hline Characteristic & $(n=68)$ \\
\hline $\begin{array}{l}\text { Years of schooling, Mean } \pm \text { SD } \\
\text { Level of education, } n(\%)\end{array}$ & $10.95 \pm 4.25$ \\
\hline$\leq 9$ years of schooling & $23(33.8)$ \\
\hline Special school & $1(1.5)$ \\
\hline Mainstream school & $22(32.4)$ \\
\hline$>9$ years of schooling & $44(64.7)$ \\
\hline $9-12$ years & $27(39.7)$ \\
\hline Higher education & $17(25.0)$ \\
\hline No data & $1(1.5)$ \\
\hline \multicolumn{2}{|l|}{ Occupation, n (\%) } \\
\hline Gainful employment & $15(22.1)$ \\
\hline Volunteer work & $1(1.5)$ \\
\hline Unemployed & $6(8.8)$ \\
\hline Student & $1(1.5)$ \\
\hline Homemaker & $3(4.4)$ \\
\hline Retired & $16(23.5)$ \\
\hline No occupation & $13(19.1)$ \\
\hline On disability benefits & $12(17.6)$ \\
\hline Other & $1(1.5)$ \\
\hline \multicolumn{2}{|l|}{ Income*, n (\%) } \\
\hline Well above average & $1(1.5)$ \\
\hline Slightly above average & $6(8.8)$ \\
\hline Average & $23(33.8)$ \\
\hline Slightly below average & $27(39.7)$ \\
\hline Well below average & $11(16.2)$ \\
\hline
\end{tabular}

SD: standard deviation; * Self-reported income, in comparison with the average income in Brazil

Despite the fact that the level of education was high for Brazil, $77.9 \%$ of the patients in our sample were not engaged in a paid job (working as a volunteer, unemployed, a student, a homemaker, retired, with no occupation or on disability benefits), $41.1 \%$ received government benefits (retirement or disability) and $55.9 \%$ declared their income to be below average (slightly below or considerably below average).

Table 3 shows the characteristics of the disabilities. Of the 68 patients evaluated, $34(50.0 \%)$ had suffered a spinal cord injury that rendered them paraplegic or tetraplegic, $38.2 \%$ had undergone amputation of one or more limbs and $11.8 \%$ had hemiplegia (due to stroke or traumatic brain injury). The 
median time since the onset of disability was 20.5 months (range, 10.5-33.5 months). Of the 68 patients, 56 (82.3\%) considered their disability to be at least moderately visible and $44(64.7 \%)$ considered it to have at least a moderate effect on their personal life. The median FIM score was 110.5 (range, 94116.5 ), and only $11.76 \%$ of the patients had an HADS-D score $\geq$ 9 (indicative of depressive symptoms).

Table 3. Characteristics of the disabilities in the sample

\begin{tabular}{lc}
\hline \multicolumn{1}{c}{ Characteristic } & $(\boldsymbol{n}=68)$ \\
\hline Type of disability, $\mathbf{n}(\%)$ & $32(50.0)$ \\
Spinal cord injury & $26(38.2)$ \\
Amputation & $8(11.8)$ \\
Hemiplegia & $20.5(10.5-33.5)$ \\
Time since onset of disability (months), median (IQR) & \\
Subjective visibility of the disability, $\mathbf{n}$ (\%) & $4(5.9)$ \\
Not visible at all & $8(11.8)$ \\
Slightly visible & $10(14.7)$ \\
Moderately visible & $16(23.5)$ \\
Highly visible & $30(44.1)$ \\
Unmistakeable & \\
Effect the disability has on personal life, $\mathbf{n}$ (\%) & $8(11.76)$ \\
Virtually no effect & $15(22.1)$ \\
Slight effect & $19(27.9)$ \\
Moderate effect & $10(14.7)$ \\
Strong effect & $15(22.1)$ \\
Profound effect & $1(1.5)$ \\
No data & $110.5(94-116.5)$ \\
FIM score, median (IQR) & \\
HADS-D score, $\mathbf{n}$ (\%) & $8(11.76)$ \\
$\geq 9$ (depression) & $60(88.24)$ \\
<9 (no depression) & \\
\hline SD standard deviation; & \\
\hline
\end{tabular}

SD: standard deviation; IQR: interquartile range; FIM: Functional Independence Measure; HADS-D: Hospital Anxiety and Depression Scale-Depression sub-scale
Table 4 shows the mean ADS-D total score $(61.29 \pm 8.75)$ and the mean scores for each of the four ADS-D sub-scalesInclusion (15.97 \pm 3.15); Discrimination (15.51 \pm 3.01); Gains $(13.43 \pm 3.54)$; and Prospects $(16.38 \pm 2.70)$-in relation to each type of disability. The attitudinal barriers, as measured by the ADS-D, did not differ significantly by type of disability ( $p>0.05$ ).

The mean ADS-D total and sub-scale scores were analysed by sex (male vs. female) and HADS-D score ( $\geq 9$ vs. $<9$ ), as shown in Table 5. An HADS-D score $\geq 9$ was found to correlate significantly with the perception of worse attitudes, as indicated by the ADS-D total score and the scores on the ADSD sub-scales Inclusion and Prospects ( $p<0.001$ for both). However, in that analysis, we found no statistically significant sex-related differences in the ADS-D results.

In the stepwise multiple linear regression analysis (Table 6), neither the time since the onset of disability nor age was found to be a predictor of the perception of attitudinal barriers measured by the ADS-D, in any of the models. In the best analysis model (which considered ADS-D total score, age, income, FIM score, HADS-D score and sex), income and depressive symptoms were found to correlate with the perception of attitudinal barriers. In the best regression model, income was the variable that correlated most strongly with the ADS-D total score.

The linear regression analysis of the factor income (Table 7) showed that there was an inverse correlation between income and the ADS-D score ( $\beta$-coefficient $=-3.91$ per income category unit; $p=0.001$ ), higher income translating to a lower attitudinal barrier, making it a facilitator of the inclusion of PWDs. The same analysis showed that for each point increase in the HADSD score, there was a -1.74 point change in the ADS-D score; in other words, the perception of attitudinal barriers increases in parallel with increasing severity of depressive symptoms ( $\beta$ coefficient $=-1.74 ; p<0.001$ ).

Table 4. Magnitude of the attitudinal barrier perceived by

\begin{tabular}{|c|c|c|c|c|c|c|}
\hline \multirow{3}{*}{ ADS-D score } & \multicolumn{4}{|c|}{ Type of disability } & \multirow{2}{*}{\multicolumn{2}{|c|}{ ANOVA }} \\
\hline & Spinal cord injury & Amputation & Hemiplegia & All & & \\
\hline & Mean \pm SD & Mean \pm SD & Mean \pm SD & Mean \pm SD & $\mathbf{F}$ & p \\
\hline Inclusion sub-scale & $15.41 \pm 3.47$ & $16.69 \pm 2.64$ & $16.00 \pm 3.11$ & $15.97 \pm 3.15$ & 1.22 & 0.3008 \\
\hline Discrimination sub-scale & $15.11 \pm 3.02$ & $16.38 \pm 2.94$ & $17.62 \pm 2.61$ & $15.51 \pm 3.01$ & 2.38 & 0.1005 \\
\hline Gains sub-scale & $13.73 \pm 3.33$ & $13.23 \pm 3.81$ & $12.75 \pm 3.77$ & $13.43 \pm 3.54$ & 0.31 & 0.756 \\
\hline Prospects sub-scale & $16.11 \pm 2.73$ & $16.69 \pm 2.5$ & $16.50 \pm 3.33$ & $16.38 \pm 2.70$ & 0.34 & 0.7160 \\
\hline Total & $60.38 \pm 9.41$ & $62.00 \pm 7.94$ & $62.87 \pm 8.95$ & $61.29 \pm 8.75$ & 0.39 & 0.6768 \\
\hline
\end{tabular}

ADS-D: Attitudes to Disability Scale for persons with physical disabilities; SD: standard deviation; ANOVA: analysis of variance

Table 5. Attitudes to Disability Scale scores, by sex and by the presence or absence of depressive symptoms, among people with physical disabilities in Brazil

\begin{tabular}{|c|c|c|c|c|c|}
\hline \multirow{2}{*}{ Variable } & \multicolumn{5}{|c|}{ ADS-D score } \\
\hline & Inclusion & Discrimination & Gains & Prospects & Total \\
\hline \multicolumn{6}{|l|}{ Sex, Mean \pm SD } \\
\hline Female & $15.17 \pm 3.73$ & $14.74 \pm 4.00$ & $13.35 \pm 3.87$ & $16.22 \pm 2.95$ & $59.48 \pm 10.86$ \\
\hline Male & $16.38 \pm 2.77$ & $15.91 \pm 2.30$ & $13.47 \pm 3.40$ & $1.47 \pm 2.59$ & $62.22 \pm 7.41$ \\
\hline$p^{*}$ & 0.18001 & 0.20397 & 0.90136 & 0.73344 & 0.28397 \\
\hline \multicolumn{6}{|l|}{ HADS-D score, Mean \pm SD } \\
\hline$\geq 9$ (depression) & $12.38 \pm 2.00$ & $12.88 \pm 2.75$ & $11.50 \pm 2.14$ & $12.75 \pm 2.82$ & $49.50 \pm 3.42$ \\
\hline$<9$ (no depression) & $16.45 \pm 2.97$ & $15.87 \pm 2.88$ & $13.68 \pm 3.62$ & $16.87 \pm 2.30$ & $62.87 \pm 8.00$ \\
\hline$p^{*}$ & $<0.001$ & 0.018329 & 0.02884 & 0.00416 & $<0.001$ \\
\hline
\end{tabular}

ADS-D: Attitudes to Disability Scale for persons with physical disabilities; SD: standard deviation; HADS-D: Hospital Anxiety and Depression Scale-Depression subscale; * Student's t-test 
Table 6. Best stepwise multiple linear regression model

\begin{tabular}{|c|c|c|c|}
\hline Variable & $\beta$-coefficient & $p$ & $95 \% \mathrm{Cl}$ \\
\hline Age & -0.143 & 0.025 & -0.27 to 0.01 \\
\hline Income & -2.292 & 0.013 & -4.09 to -0.49 \\
\hline FIM score & -0.059 & 0.033 & -012 to 0.00 \\
\hline HADS-D score & -1.54 & 0.000 & -2.08 to -1.00 \\
\hline Sex & -2.06 & 0.227 & -5.43 to 1.31 \\
\hline Model & 87 & 0.000 & 76.93 to 97.20 \\
\hline \multicolumn{2}{|c|}{$r^{2}: 0.50$} & \multicolumn{2}{|c|}{$r^{2}$ adj: 0.46} \\
\hline
\end{tabular}

Cl: confidence interval; $r^{2}$ : coefficient of determination; $r^{2}$ adj: adjusted coefficient of determination; HADS-D: Hospital Anxiety and Depression ScaleDepression sub-scale

Table 7. Linear regression analysis of Attitudes to Disability Scale scores in relation to income level and depression

\begin{tabular}{lcc}
\hline \multicolumn{1}{c}{ Factor } & $\begin{array}{c}\text { ADS-D score } \\
\text { Mean } \pm \text { SD }\end{array}$ & Linear regression \\
\hline Income level* & & \\
Well above average & $76 \pm 0$ & $\beta=-3.91$ \\
Above average & $64 \pm 7.23$ & \\
Average & $63.95 \pm 8.53$ & \\
Below average & $60.92 \pm 7.2$ & $\mathrm{p}=0.001$ \\
Well below average & $53.81 \pm 9.33$ & \\
HADS-D score & $61.29 \pm 8.75$ & $\beta=-1.74$ \\
& & $\mathrm{p}<0.001$ \\
\hline
\end{tabular}

ADS-D: Attitudes to Disability Scale for persons with physical disabilities; SD: standard deviation; B: coefficient of linear correlation; HADS-D: Hospital Anxiety and Depression Scale-Depression sub-scale; * Self-reported income, in comparison with the average income in Brazil

\section{DISCUSSION}

In the present study, we have shown that PWDs in southeastern Brazil perceive some attitudinal barriers to their functioning. However, the mean ADS-D score in our sample (61.29) was higher than the 50.2 and 58.3 reported in surveys conducted in China and in the southern region of Brazil, respectively, ${ }^{10,11}$ indicating that the magnitude of the perceived attitudinal barrier was lower in our sample. The scores on the ADS-D sub-scales Discrimination, Inclusion and Prospects were also higher in our sample than in those evaluated in previous studies, possibly because our sample was composed of PWDs who had access to multidisciplinary rehabilitation. Although the ADS-D has a low risk of cultural biases (with multicentric and transcultural characteristics), political, social and organisational factors in health care systems can be immeasurably important as possible causes of the discrepancies between our findings and those of other authors. Data show that only $35.6 \%$ of the PWDs in China have had access to health care services during their lifetime, only $8.5 \%$ having had access to rehabilitation services. ${ }^{9}$

The PWDs evaluated in the present study were treated at a centre for physical and rehabilitation medicine. Therefore, our data represent the reality of those with access to health care and rehabilitation services, which means that they might not be comparable to those obtained for PWDs in China. Unlike the study in which the ADS was validated for use in Brazil, which was conducted in the state of Rio Grande do Sul and included individuals with visual impairment, hearing impairment and stroke sequelae, ${ }^{11}$ the present study focused on physical (motor) disability. Our sample was composed primarily of PWDs with spinal cord injury, followed by those who had undergone amputation and those with hemiplegia, although it included a limited number of hemiplegics, because cognitive impairment, which often accompanies hemiplegia, was one of the exclusion criteria.

Despite the fact that the study validating the ADS for use in Brazil recommended analysis of sub-scale scores, ${ }^{11}$ the authors of the original scale, ${ }^{8}$ as well as those of other studies employing the scale, ${ }^{10}$ have shown that it is possible to evaluate the perceptions of PWDs on the basis of the ADS total score. Therefore, we chose to analyse the sub-scale scores and total scores.

Although the proportion of patients with depressive symptoms in our sample was small, it was sufficient to demonstrate a correlation between depression and greater perception of attitudinal barriers. That is in keeping with the findings of Bredemeier et al., ${ }^{11}$ who demonstrated that depression affects the way in which PWDs perceive the attitudes of other people. In the present study, we discussed the question of which comes first, depressed people perceiving greater attitudinal barriers or exposure to such barriers causing people to become depressed. To determine causality, there is a need for a different type of study that would consider the temporality of exposure.

The results of the present study also suggest that income is a facilitator of PWD inclusion and reduces the perceived magnitude of attitudinal barriers. Previous studies have also suggested that social class plays a role in the perception of attitudes toward disability. ${ }^{11}$ In the previously cited study conducted in China, the perceived magnitude of attitudinal barriers was lower among PWDs who had had their disability for more than ten years. ${ }^{9}$ In contrast, in our sample, there was no statistically significant relationship between the time since the onset of the disability and the ADS-D score. That suggests that, in Brazil, the attitudinal barrier is perceived at the very beginning of the disability, persisting due to a lack of changes in others or to an evolution to depressive symptoms.

In our sample, we observed no correlation between functionality and the perceived magnitude of the attitudinal barrier. We also found that the type of disability did not correlate with the perceived magnitude of the attitudinal barrier (ADS-D total score) or with any of its facets (ADS-D subscale scores). These findings are relevant because they indicate that the disability itself, regardless of other variables, such as the time since the onset, type or severity of the disability, or the sex of the individual, affects the perception of the attitudinal barrier. Our results differ, in part, from those of the study conducted in China, which showed that the severity of the disability can affect quality of life directly and indirectly, through the quality of care and attitudes toward disability, quality of care playing the more important role. ${ }^{9}$ In the present study, sex did not correlate with the perceived magnitude of the attitudinal barrier. Although our sample included a small number of women, we observed atendency for the perceived magnitude of the attitudinal barrier to be greater among the women than among the men. 
That merits further study, given that questions of ethnicity, religion, sex, sexual orientation and economic status can all increase vulnerability to discrimination. ${ }^{2}$

Our study has some limitations. Because of its crosssectional design, causal relationships could not be established. Nevertheless, this was the first study of its kind to be conducted in Brazil and to study attitudes in a quantitative way, through application of the ADS-D, as well as being the first such study to be carried out exclusively at a rehabilitation centre.

Physical barriers are considered to originate from attitudinal barriers (for example, if access ramps are lacking, it is because the attitudes of those who should advocate for them do not favour their implementation). In view of that idea, one of the strengths of this study was that we quantified the attitudinal barrier by questioning the victims, ${ }^{8}$ who daily suffer the effects of negative attitudes toward disability, materialised in the quality and quantity of the services and care they receive, ${ }^{19}$ rather than the aggressors (who do not perceive the harm).

People with physical disabilities report attitudinal barriers to functioning. Disability itself appears to generate attitudinal barriers regardless of sex, degree of functional independence, the type of disability or the time since the onset of the disability. Income level and depressive symptoms both appear to influence how much PWDs perceive or suffer from attitudinal barriers, income level reducing the perceived magnitude of such barriers and depression increasing that perception.

\section{REFERENCES}

1. Organização Mundial de Saúde. CIF: Classificação Internacional de Funcionalidade, Incapacidade e Saúde. São Paulo: EDUSP; 2003.

2. World Health Organization. World report on disability. Geneva; WHO; 2011.

3. Chade MLMN. Imperfeitos e esquecidos: os deficientes físicos, sua condição, barreiras e atitudes no município de São Paulo [Dissertação]. São Paulo; Fundação Getúlio Vargas; 1988.

4. Ajzen I. Nature and operation of attitudes. Annu Rev Psychol. 2001;52:27-58 Doi: https://doi.org/10.1146/annurev.psych.52.1.27

5. Copestake $P$, Sheikh $S$, Johnston $S$, Bollen A. Removing barriers, raising disabled people's living standards. London: Ipsos MORI; 2014.

6. Pacheco KMB, Alves VLR. A história da deficiência, da marginalização a inclusão social: uma mudança de paradigma. Acta Fisiatr. 2007;14(4):242-8. Doi: https://doi.org/10.11606/issn.2317-0190.v14i4a102875

7. Fechio MB, Pacheco KMB, Kaihami HN, Alves VLR. A repercussão da lesão medular na identidade do sujeito. Acta Fisiatr. 2009; 16(1):38-42.

8. Power MJ, Green AM; WHOQOL-DIS Group. The Attitudes to Disability Scale (ADS): development and psychometric properties. J Intellect Disabil Res. 2010;54(9):860-74. Doi: https://doi.org/10.1111/j.1365-2788.2010.01317.x
9. Zheng QL, Tian Q, Hao C, Gu J, Lucas-Carrasco R, Tao JT, et al. The role of quality of care and attitude towards disability in the relationship between severity of disability and quality of life: findings from a cross-sectional survey among people with physical disability in China. Health Qual Life Outcomes. 2014;12:25. Doi: https://doi.org/10.1186/1477-7525-12-25

10. Zheng Q, Tian Q, Hao C, Gu J, Tao J, Liang Z, et al. Comparison of attitudes toward disability and people with disability among caregivers, the public, and people with disability: findings from a cross-sectional survey. BMC Public Health. 2016;16(1):1024. Doi: https://doi.org/10.1186/s12889-016-3670-0

11. Bredemeier J, Agranonik M, Perez TS and Fleck MPA. Evidence of Validity of the Brazilian Version of ADS: of Attitudes towards Disabilities. SM J Community Med. 2015;1(1):1002.

12. Bredemeier J, Agranonik M, Perez TS, Fleck MP. Brazilian version of the Quality of Care Scale: the perspective of people with disabilities. Rev Saude Publica. 2014;48(4):583-93. Doi: https://doi.org/10.1590/s00348910.2014048005056

13. Bredemeier J. Qualidade de vida, qualidade de cuidado e atitudes frente a incapacidade em pessoas com incapacidades físicas e intelectuais [Tese]. Porto Alegre: Universidade Federal do Rio Grande do Sul; 2013.

14. Zigmond AS, Snaith RP. The hospital anxiety and depression scale. Acta Psychiatr Scand. 1983;67(6):361$70 . \quad$ Doi: https://doi.org/10.1111/i.16000447.1983.tb09716.x

15. Castro MM, Quarantini L, Batista-Neves S, Kraychete DC, Daltro C, Miranda-Scippa A. Validity of the hospital anxiety and depression scale in patients with chronic pain. Rev Bras Anestesiol. 2006;56(5):470-7. Doi: https://doi.org/10.1590/s0034-70942006000500005

16. Marcolino JA, Mathias LA, Piccinini Filho L, Guaratini AA, Suzuki FM, Alli LA. Hospital Anxiety and Depression Scale: a study on the validation of the criteria and reliability on preoperative patients. Rev Bras Anestesiol. 2007;57(1):52-62. Doi: https://doi.org/10.1590/s003470942007000100006

17. Granger CV, Hamilton BB, Keith RA, Zielezny M, Sherwin FS. Advances in functional assessment for rehabilitation. Topics Geriatr Rehabil.1986;1(3):59-74.

18. Riberto M, Miyazaki MH, Jucá SSH, Sakamoto $H$, Pinto PPN, Battistella LR. Validação da Versão Brasileira da Medida de Independência Funcional. Acta Fisiatr. 2004;11(2):72-6.

19. Gill F, Stenfert Kroese B, Rose J. General practitioners' attitudes to patients who have learning disabilities. Psychol Med. 2002;32(8):1445-55. Doi: https://doi.org/10.1017/s0033291702006608 